\title{
Mask Is a Double-edged Sword in the Fight Against COVID-19 Pandemic
}

Jianqing $\mathrm{Wu}^{1}$, Ph.D., J.D. and Ping Zha ${ }^{2}$, M.D. (Chi. Med.)

March 28, 2020

(Preprint for comments, NOT published)

Correspondence: tempaddr2@atozpatent.com

1. End the Incurable Era (Independent researcher for cause), P. O. Box 689, Beltsville, MD 20704. www.igoosa.com.

2. Independent Researcher (Not affiliated with any entity), can be reached by using the above address.

Keywords: coronavirus, COVID-19, mask use, disease severity, transmission route, lung damages, cold flu influenza

\section{ABSTRACT}

The COVID-19 pandemic has become out of control. To determine whether the lack of protection of lungs is a factor for the rapidly increasing infected population, we constructed a mask use model and analyzed how viral particles behavior. We found that mask can prevent viral particles from crossing it, reduce oxygen uptake efficiency, raise inlet air temperature, and increase resistance to breathing. We found that uninfected people should wear masks in any closed public building where viral particles from infected persons are expected to exist; that masks can dramatically aggravate disease severity on infected persons; that use of masks by infected persons is justified only if cross-infection and successive infections from external viral sources outweigh the expected harm; that people with unknown infection status should exercise due care. We further found at this point no fast measure can break the chain of infection, social distancing rule is insufficient, and wearing masks is the only effective remedy for interim protection. We found that World Health Organization's rules on the use of masks are largely incorrect, and so are the rules of the Centers for Disease Control and Prevention in the U.S. We predicted that those rules have dramatically increased severe infection incidence rate, and have made COVID disease of infected persons much severer. We personally noted that a big percent of Americans still do not wear masks in closed public areas, and leave the most lethal transmission route open. If masks are not correctly used, the U.S. and many Western nations 
will sustain the worst damages in all aspects from human life and economic activities.

\section{INTRODUCTION}

At the time of writing this article, there are 571,678 total cases, with 26 494 deaths in nearly 199 countries [1]. At least most countries have reported cases. In the U.S., 103,321 infection cases with 1,668 deaths were reported in 54 states [2]. So the increase in new cases is so fast that we must examine every measure that has been used in the fight against the pandemic. We have extensively evaluated the disease severity on a kinetic framework in prior studies $[3,4]$. We have noted personally that most Americans have paid great attention to avoiding physical contacts, but few of them wear masks even in public places such as groceries, stores and public arenas. We suspected that failure of using proper lung protection is the main reason for the rapid increase in new cases. Since the details of viral spread within lungs are not the kinds of research that can be done under the medical research model, we will examine the role of masks by establishing simple models for visualization.

\section{MODEL ANALYSIS AND RESULTS}

\section{A. Implications That Disease Severity Depends on Viral Concentrations}

Classical infection theories imply that viral infection is a number game. Per classic model, the actual number of viral particles that enter any given cell is a statistical process: some cells may absorb more than one infectious agent while others may not absorb any [5]. Cells infected by at least one viral particle increase when more viral particles are present. This model implies that as the viral concentration increases, the percentage of cells infected with at least one viral particle increases. When more cells are infected, the virus can cause severer damages. Even though this model does not directly address disease kinetics, it implies that viral number determines infection degree.

While a virus may operate independently from other viral particles [6], viral spread is often facilitated by groups of viral genomes, such as polyploid virions, aggregates of virions, virion-containing proteinaceous structures, secreted lipid vesicles, and virus-induced cell-cell contacts. These multi-genome structures may promote virus-virus interactions and the evolution of social-like traits $[7,8,9,10]$. Those properties imply that infection requires certain viral concentration, and may require more time to form infectious structures. When viral concentration is highly diluted, it is impossible to form infectious structures or at least could take more time to form the infectious structures. 


\section{B. Airborne Viral Particles}

We safely assume that infected humans can generate airborne viral particles based on three lines of facts: human tidal breathing tests, animal influenza research, and observed cases on transmission routes.

\section{Human tidal breathing}

Based on many studies on influenza, normal (tidal) breathing can shed viral particles by the exhaled air [11]. Exhaled influenza virus RNA generation rates range from 3.2 to 20 influenza virus RNA particles per minute and over $87 \%$ of particles exhaled were under $1 \mu \mathrm{m}$ in diameter. In a closed small room, the viral concentration can rapidly rise (add about 28,800 RNA copies/day for influenza virus). Influenza virus could be detected in the exhalations of infected persons during normal tidal breathing or talking but not during coughing [12]. Later studies showed that respiratory particles by influenza patients were produced while breathing or coughing, but not both maneuvers side-by-side [13, 14, 15]. The scattering data and conflicts demonstrate that the exact number of viral particles a person can generate may depend on many factors.

Bacteria and viruses can travel through the air. When someone sneezes or coughs, tiny mucous droplets filled with viruses or bacteria scatter in the air. The expelled air can travel at the initial speed of 75-100 miles per hour [16]. In air samples collected from a school during an influenza season, influenza A virus was detected in densities ranging from $2.0 \times 10(-1)$ to $1.9 \times 10(4)$ (gene copies $\mathrm{m}-3$ air) [17]. Infection could be caused by exposure to the air containing 23586 gene copies for 8 hours.

Whether influenza virus can be transmitted by airborne particles and what concentration can cause infection have been studied for years [14, 15]. The answer depends on a large number of factors such as viral nature, viral concentration, viral out-of-the-body survival time, exposure time, humidity and temperature, host health, etc. "Conflicting" conclusions regarding the relative importance of airborne, droplet, and contact-based spread among humans [18, 19] are natural. Disease severity naturally depends on exposure to and thus immunity against influenza virus; and immunocompromise affects influenza viral reproduction [20, 21, 22, 23, 24, 25]. When at least one variable is not controlled or omitted, studies naturally reach different conclusions.

2. Airborne viral particles in animal studies

Several animal studies provide useful hints. Influenza A virus can exist in all particle size ranges in quantities ranging from 5.5x10(2) (in particles ranging from 1.1 to $2.1 \mu \mathrm{m}$ ) to $4.3 \times 10(5)$ RNA copies $/ \mathrm{m}(3)$ in the largest particles (9.0$10.0 \mu \mathrm{m})$ [22]. Porcine epidemic diarrhea virus was detected from $1.3 \times 10(6)$ $(0.4-0.7 \mu \mathrm{m})$ to $3.5 \times 10(8) \mathrm{RNA}$ copies $/ \mathrm{m}(3)(9.0-10.0 \mu \mathrm{m})$. Porcine epidemic diarrhea virus (PEDV) can be detected in a room containing infected pigs and at various distances from the outside of swine farms experiencing PEDV outbreaks [26]. Infectious PEDV was found in the air from experimentally infected pigs up 
to 10 miles downwind from naturally infected farms at the concentration of $7.98 \times 10(3)$.

Viruses were detectable in association with aerosolized particles. Proportions of positive sampling events were 69\% for PEDV, 61\% for HPAIV, and $8 \%$ for PRRSV. For all 3 viruses, higher numbers of RNA copies were associated with larger particles [27]. Influenza virus RNA was detected in air samples collected between 1.5 and $2.1 \mathrm{Km}$ away from the farms with viral levels significantly lower at $4.65 \times 10$ (3) RNA copies $/ \mathrm{m}^{3}$ [28]. Pigs can be a source of infectious aerosols of Influenza A virus. Such aerosols can be exhausted from pig barns and be transported downwind to a long distance [29]. Some of these viral particles are infectious. The viral concentration depends on viral source and distance from the source. The viral concentration is $5.71 \times 10(7)$ in oral fluid, $8.32 \times 10(4)$ inside air, and $4.57 \times 10(4)$ in exhaust air. Relative to the oral fluid, virus in the inside air is diluted by about a thousand times and exhausted air has a further lower viral concentration.

Notwithstanding some conflicting findings in other viruses [30], COVID-19 virus can be transmitted through air efficiently beyond disputes.

\section{Assumptions Used in Our Models}

Based on hints of animal studies, human influenza studies and our personal observations, we assume that COVID-19 viruses from infected persons can exist as airborne particles (we do not need to resolve exact form of particles in this study), can travel long distances, and can infect health persons. We further assume that it is impossible to totally avoid them. The chain of infection cannot be broken by identifying and isolating infected persons. Thus, the only realistic strategy is to mitigate the pandemic by reducing disease severity. We consider the following facts.

1. Vulnerability of lungs to viral attacks

Human lungs are the most fragile vital organs based on data from Guyton [16]. First, they normally have almost 600 million alevoli. The total inner surface area is about $70-100 \mathrm{~m}^{2}$. Each alveolus may be made of 40 type I cells and 77 type II cells [31]. So, the lungs have about 70 billion epithelial cells that are exposed to the internal air way. The epithelial cells are fragile and vulnerable as if they were exposed to air in back doors. If we view blood circulation as the protective means, the virus can enter epithelial cells, infect them, and damage them without activating the adaptive immune response. An implication is that, if an airborne viral particle has successfully evaded all defense mechanisms in the respiratory track, the particle will get into the alveolar space, get out of the space by only a small chance, and most probably land on an epithelial cell. This also implies that lungs have potentially a large number of target cells for each viral particle to hit. 
The airway structure is well structured channels for redistributing viral particles from the common areas to alveoli, from any part of the lungs to other parts of the lungs, and from infected alveoli to uninfected alveoli. Viral particles entering passing through the trachea can be distributed to any of the alveoli purely by chances. After a viral particle has entered a nostril, it most probably eventually hits bronchi wall or gets into an alveolar space. This structure guarantees that some viral particles originated from any alevoli can be sucked back, reaching other alveoli through alveolar ventilation. This structure explains why infection of a part of the lungs can spread to the whole lungs quickly.

A third problem is that the lungs must work continuously. Oxygen cannot be stored in any buffer so as to allow the lungs to take a break. They must work continuously from the person's birth to death. This functional nature raises infection chance by precluding the small probability theory from being applied. Breathing in viral-containing air a few times may be harmless, but breathing the same air in a few hours can lead to serious disease. This time-dependent infection chance has a determinant impact on disease severity. In each breathing cycle, viral particles originated from infected cells are exhaled to a common space of the respiratory track in an exhaling cycle, and then are sucked back to the lungs, reaching deep bronchi membrane followed by further move into other alveoli by alveolar ventilation. Based on the total volume of $500 \mathrm{ml}$ of tidal breath and $150 \mathrm{ml}$ of dead space, the virus may be diluted by 3 to 4 times by outside air. Thus, normal breathes could redistribute about 1 to 6 RNA particles per minute within the lungs for influenza virus [12]. In fact, the time-dependent nature guarantees that re-infection and successive infection can gradually spread the virus from infected regions to substantially all uninfected regions of the lungs unless the acquired immune response can inhibit viral activities.

The respiratory structure and time-dependent viral redistribution greatly favor viral spread within the lungs. Notwithstanding those two weaknesses, nothing can alter the critical role of viral concentration. If a small number of viral particles contact lung tissue, they probably cannot cause serious damage to the lungs. The body has many levels of defense mechanisms. If just one or a few alveoli are infected, the body may clear up the virus by host responses or innate immune responses. When both host responses and innate immune response fail to control viral reproduction, disease outcome depends on relative speeds between the viral reproduction process and the immune response.

We previously proposed a re-infection concept [3]. As implied by collective infection theory, both viral number and mutants can increase viral virulence. Lungs can defend against a limited number of viral attacks. The epithelial cells cannot be immersed in blood fluid because the alveolar inner surface must be kept try. Thus, blood does not do much to stop the virus from entering the cell. This means that those cells are susceptible to viral attacks even after acquired immune has developed. The re-infection is more important because the COVID19 virus mutates rapidly or has changed, and has generated 1111 strains as on March 24, 2020 [Sup. n1]. 
In the contest between viral reproduction and immune response, the viral number is a determinant factor. If the virus attacks only one or a few spots in the $100 \mathrm{~m}^{2}$ inner surface or 70 billion cells, the infection can generate a small number of viral particles for redistribution. It would take a relatively long time for the infection to reach the whole lungs. However, if a large number of viral particles attack thousands to millions spots in the lungs at substantially same time, the virus can spread to the whole lungs more quickly. This number law must be true whether the virus spreads by cell-to-cell contact or by breath-driven re-infection process. For the obvious reason, exposure to a small number of viral particles may result in a mild disease, but exposure of the lungs to a large number of viral particles can be lethal.

\section{Effects of Masks on Lung Functions}

Masks are used with an assumption to prevent the virus from passing through it when they are used to prevent COVID-19 infection. Whether a mask does good or evil depends on where the virus comes from and whether viral concentration in the ambient air is higher or lower than the viral concentration inside the respiratory track. Net effect depends on who wears the mask and under what circumstance the mask is worn. In addition, a mask has other effects on health.

\section{Masks can filter out some viral particles from external air}

We use a simple model to show how a mask prevents the virus from entering into the respiratory track and the lungs when the mask is worn by an uninfected person who breathes in ambient air that contains the virus (See Figure 1 below).

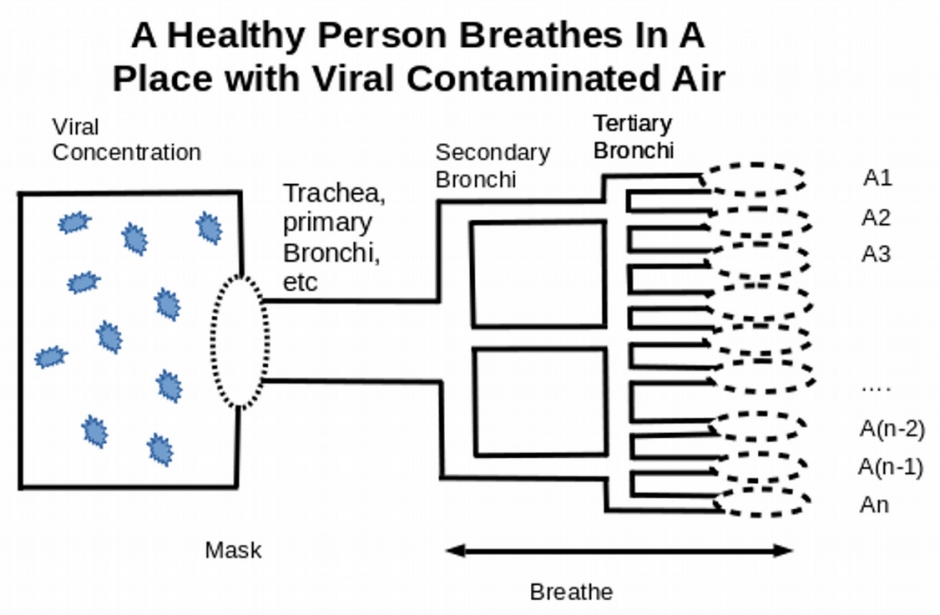

Figure 1. In this model, viral particles (which are shown in an exaggerated size for clarity) exist only in the external air while the respiratory track does not 
have any virus. When the person breathes, viral particles from the air are filtered out by the mask. Some viral particles may stick to the outer surface of the mask while some small particles may penetrate into the mask middle layers. Naturally, some small viral particles may pass through the mask and eventually get into the respiratory track. Their final fates depend on luck, host responses, and innate immunity.

\section{An infected person should NOT wear a mask with several exceptions}

Figure 2 shows how a mask can keep viral particles from getting out of the lungs when an infected person wears it in a place, where air is not contaminated by the virus.

Figure 2 shows that alveoli 1, 2 and 3 are infected, and shed viral particles that are moving along the respiratory track. Since the viral particles cannot pass through the mask, some of them stay on the inner surface and some of them stay in the voids between the mask and the nostrils. The viral concentration inside the respiratory track will rise with time to reach some sort of dynamic equilibrium. The viral concentration in the respiratory track depends on the number of infected sites, viral reproduction speeds, breathing mechanical properties, etc. We anticipate that the viral concentration in the respiratory track from thousands of infected cells is much higher than that from a few infected cells.

Insert (b) shows how the exhaling cycle forces viral particles to move toward the nostrils, but due to the barrier of the mask, they cannot get out except that a very small number may squeeze through. Some viral particles stick on the mask inner surface while others are bounced back to the respiratory track.

Insert (c) shows that an inhaling cycle sucks viral particles back to the lungs. Due to mixing of fresh air, the viral concentration is diluted slightly. The virus may be inhaled to reach tertiary bronchi. Some viral particles may strike any part of the respiratory track, and some may get into other alveoli. The insert (c) shows that the sucked-back viral particles hit three previously uninfected alveoli, An, A(n-1) and A(n-2). As a result, more lung tissues are infected, and disease severity is increased. We assume that re-infection can cause viral spread to distant areas (e.g., from the upper left lung to the lower right lung). Viral redistribution is the most powerful means to get the whole lungs. Without this reinfection process, viral spread could have to depend on cell-to-cell contact or blood circulation.

Insert (c) also shows that viral particles from an infected alveolus A1 can be redistributed to an infected alveolus A3. Infection of a previously infected cell may be an aggravating factor because the virus is rapidly mutating. It is possible that the virus in alveolus A1 is different from the virus in alveolus A3 (their physical locations can be anywhere in the lungs) in some aspects. Thus, the viral mutants from alveolus A1 in combination with the virus in alveolus A3 may be more infectious. Moreover, if the lungs have been able to resolve the infection in 
the alveolus A3, the newly arrived virus may revive viral reproduction activity at alveolus $\mathrm{A} 3$ and thus turns a healing process into a mew disease process.

\section{For An Infected Person}

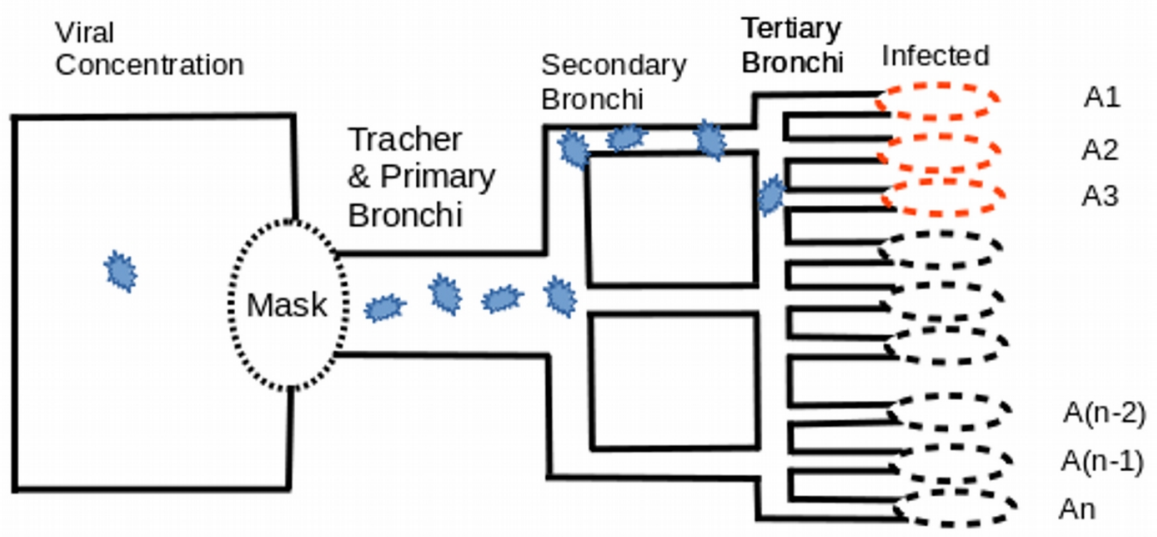

(a) Three Originally Infected Alveoli
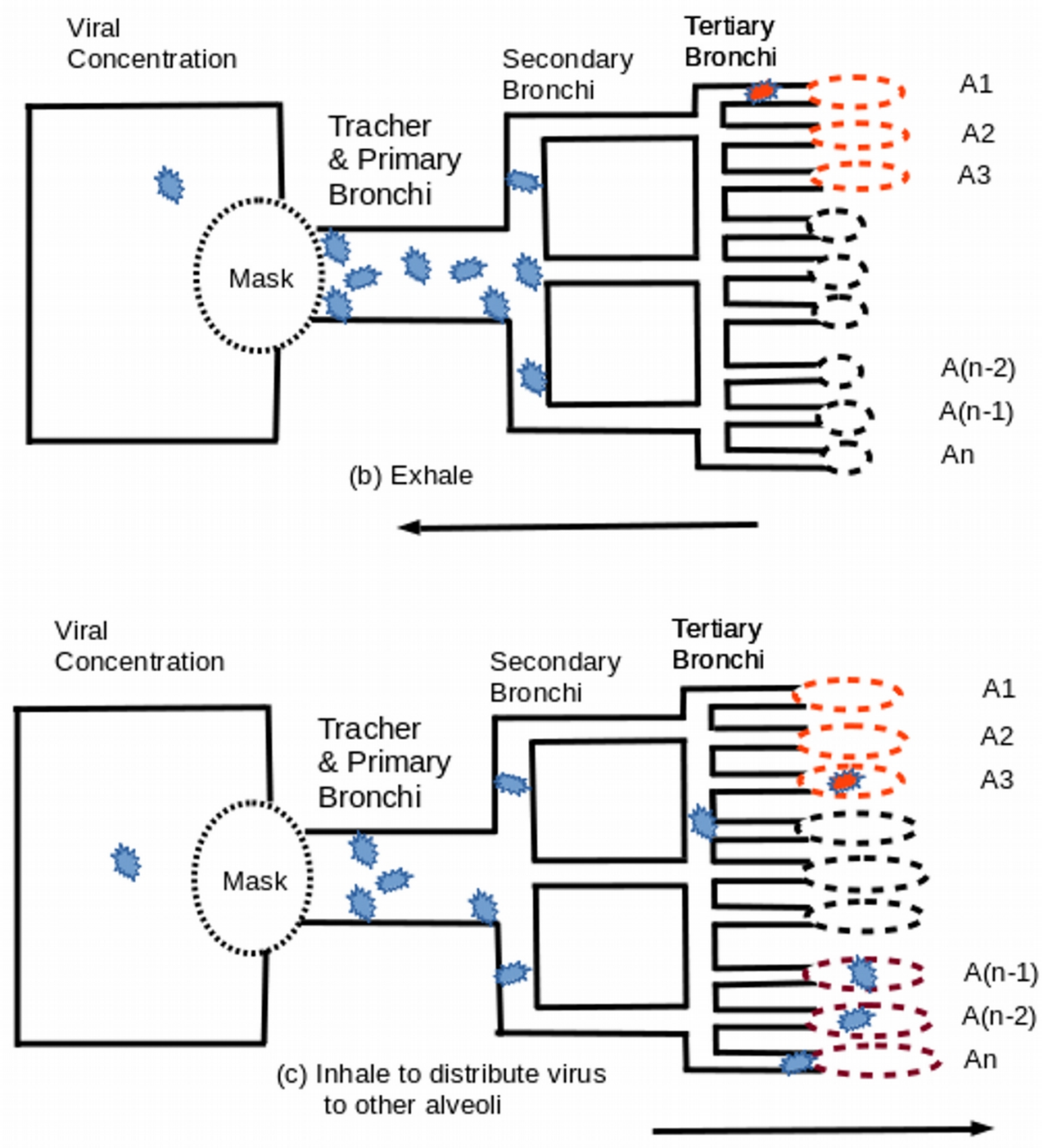

(C) All right reserved, Wu \& Zha v100 8 
Figurea 1 and 2 show only several alveoli for illustration purpose. They should be interpreted by considering 600 million alveoli, comprising about 70 billion epithelial cells with a total surface area of 70-100 squired meters.

Lungs are big organs in the human being. Initial viral attack may be limited to a relatively small region or several small regions except in cases involving severe exposure. Disease severity can be effectively mitigated by slowing down the re-infection process. However, wearing a mask is like keeping all internal viral particles to within the respiratory track. An infected person with a mask is a perfect system for raising internal viral concentration. If any part of the lung tissue is infected, this part of tissue sheds viral particles continuously within a time window. Since generated viral particles cannot get into the air due to the barrier of the mask, most of the viral particles get back to the lungs in inhaling cycles. As a result, the viral concentration in the respiratory track rapidly goes up. The breathing cycles redistribute generated viral particles among all spaces in the lungs. When a subsequently-infected alveolus starts shedding virus, the viral particles are added to the existing viral particles in the respiratory track. Eventually, the lungs reach a dynamic equilibrium at which all points in the respiratory track including all alveolar spaces have the similar viral concentration.

In the case that an infected person wears no mask, most viral particles are discharged into the air. In each exhaling cycle, all viral particles carried in about $500 \mathrm{ml}$ air are completely discharged into the air. If we sum all viral number up for a day or several days, the total number of discharged viral particles is very large. The adverse effect of wearing the mask is expected to be big. For this reason, an infected person must not wear a mask in the time window that the lungs are actively shedding viral particles.

3. When the inside and outside viral concentrations are close

As a general rule, wearing a mask is good only if the outside viral concentration is higher than the inside viral concentration. Human health problem is often not a clear-cut problem. A healthy person may get infected and thus becomes an infected person without knowing the time of infection. Conversely, an infected person may clear up the virus and thus becomes a healthy person. In addition, the outside viral concentration is a variable that cannot be determined reliably. However, one still can make sound and rational decisions in many situations.

4. The effects of masks on oxygen and carbon dioxide exchanges

A mask adds additional volume to the dead space of breathing. Some of the air in the voids between the mask and the nose and mouth is sucked back to reach bronchi and alveoli by alveolar ventilation.

In a very cold day, mask can keep the lungs warmer. The mask can reduce heat dissipation from the covered area on the face. When the nose and mouth are kept warmer, they warm up air that is inhaled. In addition, mask also adds 
additional space to the dead space. Some exhaled air stays in voids between the nose and the mask. This portion of air is warmer and is mixed with incoming air to raise air temperature. When low temperature is a big hazard, the mask can improve lung functions.

5. Masks make breathing more difficult

When a mask is worn, the air must pass small holes in the mask. This obviously increases resistance to air flow. For a person with poor lung function, the mask diminishes lung function. If the lung function is already near the disability level, it can have adverse impacts.

\section{E. DISCUSSION}

Whether wearing a mask is beneficial or not depends on relative viral concentrations in the respiratory track air and the ambient air. If the viral concentrations were identical and if their viral RNA variants were not a factor, wearing a mask has no benefit in controlling viral exposure. In evaluating mask benefits, we must consider viral RNA variants and other types of viruses that promote COVID infection in the lungs.

\section{Uninfected persons in places with airborne viral particles}

In a case when a healthy person is visiting a hospital or a public area that contains a significant amount of viral particles from infected persons, mask is the most powerful tool for preventing lungs from being infected. Since no mask can ever filter out the virus completely, it is all about viral number or total viral particles that reach deep bronchi and hit alveoli. Final results depend on how many viral RNA copies are inhaled and how long the exposure lasts. Since the lungs have limited innate defense capacity, the lungs may be able to overcome viral amounts from one breath, but cannot handle the viral amount that is breathed from the same air for hours. When the ambient air contains extremely low viral concentration, a mask may extend exposure time to hours without posing a real risk.

Tolerable exposure for a person depends on a large number of other factors. If the person's health condition and immune system are in a top shape, the person is able to resist viral attack better than when the person is in a poor health. Most important aggravating factors are temperature, air humidity, and emotional condition. Temperature can directly affect blood vessel diameters; humidity affects oxygen-carbon dioxide exchange efficiency; and emotion state affects immune functions and blood vessel conditions.

Social distancing rule can effectively prevent an infected person from infecting a healthy person from droplets and viral particles from the infected persons. This measure eliminates the most lethal transmission route. However, this measure is not effective to stop the viral particles that have been suspended in the air from infecting healthy persons. Even if the viral concentration in the 
air is not very high and the virus gradually loses activity, extended exposure may still pose risk to certain people.

Mask should be used by an uninfected person in the following situations:

(a) In hospitals, quarantines and isolated homes, air contain relatively high viral concentrations in different mutants plus other disease agents, wearing a mask may reduce infection risks.

(b) Uninfected people who shop in groceries, poorly ventilated open public spaces, and closed office buildings in a pandemic season should wear masks and reduce the duration of exposure.

(c) Uninfected persons should wear a mask anywhere infected persons probably appear. Whether such a person gets infected depends on personal health condition and other factors such as temperature, humidity, foods, and emotion condition.

Uninfected persons should not wear a mask in the following situations:

(a) An uninfected person in an open space without other people, wearing masks do not produce good benefits unless mask is used to filter out pollen or dusk, or as a mean to warm up inlet air in a cold day.

(b) Do not wear a mask in a widely open space with few or no other human beings. Even if a few viral particles may come from the wind, they most probably have little or no infectious power. Even if a single viral particle gets into the respiratory track, it may be cleared by defense mechanisms.

(c) In a widely open area where a limited number of infected persons and non-infected persons work together, infected persons should not wear masks so that the virus will not be redistributed to other parts of the lungs. Weather the uninfected persons should wear a mask depends on wind direction and relative positions of infected persons and uninfected persons. A small wind or good air ventilation can quickly drive virus-carrying air away from the breathing space of health persons.

\section{Infected persons}

For infected persons, the benefits of masks are judged by comparing the viral concentration and composition in the ambient air and those in the air from the respiratory track of an infected person.

The most important factor considered is the time window for redistributing the virus by the re-infection process. After an initial infection, viral reproduction scale may be limited due to the small size of infection. The lungs start shedding virus, which most probably starts activating the adaptive immunity. When the immune system has reached a certain level, viral reproduction will be brought under control. Re-infection may take place in a small time window. It is obvious that the scale of re-infection and speeds of re-infection process determine the 
degree of lung damages as well as damages to other organs. This time window is most probably one or a few days before the sign of symptoms to the point what the entire lungs are completely infected. The re-infection speed and initial infection scale (the points of seed infection) determine how rapidly the lung condition degrades.

(a) If the infected person is in an open space or without the risk of crossinfection from other types of virus, wearing a mask can only promote re-infection of uninfected alevoli by patient's own virus.

(b) In personal isolation, wearing a mask most probably hurts the person. The mask help patient-own virus reach the maximum viral concentration.

(c) From the earliest signs or suspected infection to a point of completing re-infection of the lungs, patients should be housed so that they can avoid wearing mask to slow down the re-infection process. What can make difference is the speed of re-infection process.

(d) After the re-infection time window is over, the potential adverse effect of re-infection by patient's own virus is a less concern, as compared with newly arrived viral particles or different types of viruses. Masks may offer benefits in some circumstances. However, a best strategy is avoiding getting into such an environment so that the patient can avoid wearing a mask.

The default rule to encourage infected persons to wear masks is questioned from a public policy ground. The death rate of infected persons is the hallmark of the danger of any pandemic disease. The top priority is to save each infected person while minimizing the risk to uninfected people. The disease can disrupt human life because the disease can cause death. If the death rate for the disease is reduced to near zero, the disease will become a tolerable illness like a mild flu. Thus, the top priority is finding cures and effective treatments for infected persons. Protecting uninfected people from being infected is just a short-term desperate attempt. It cannot work on a long-term basis because this disease eventually infects everyone.

\section{Persons with uncertain infection statuses}

There is always an uncertain time as to when an uninfected person is infected by the virus. When a person is infected and starts shedding viral particles, there is a point to change the relative viral concentrations in the external air and internal air. If the air in the respiratory track has higher viral concentration than does the air from the ambient, wearing a mask can harm the person. The change point depends on many factors. If viral concentration attributable to infected lungs is lower than that in the inhaled air, or if external air contains virulent viral mutants or other highly infectious viruses, wearing a mask may have net benefits. If the outside air is cleaner than the air in the respiratory track, warning a mask can only hurt the person.

4. Tradition of not using masks 
As of March 26, 2020, we still saw shoppers did not wear masks in grocery stores, department stores and home product stories. Stories took measures to limit the density of shoppers and required them to follow the 6 feet social distancing rule. This rule can eliminate the worst transmission risks, but cannot eliminate all transmission risks. When the viral concentration in the air has reached a certain level, the air can infect shoppers or visitors. The air can pose risk if the total number of viral particles inhaled is more than what the shoppers' defense systems can handle. Considering other exposure scenarios, we found that the failure to use masks among uninfected people is the main reason for continuous rise in positive cases.

\section{Homemade masks}

When no mask is available on the market, people should be enabled to make and use homemade masks. A mask comprising several layers high-density cotton cloth with one or two coffee filter papers or other suitable papers inside may capture big droplets and even some of small airborne particles. In each exhaling cycle, some small viral particles from the respiratory track are captured on the inner surface of the mask. When the mask is used for a long time, large droplets are accumulated on the outside surface while some small particles are caught on the inner surface with some of them getting into the middle layers. The mask can capture good percent (but not all of them) of the droplets and airborne particles that could have reached the respiratory track and landed on lungs cells. The mask must have partial protection. To improve efficiency, homemade masks should be washed and heat-dried frequently for reuse.

The benefits of masks should be weighed quantitatively: reducing viral number entering the lungs by as much as possible. If a person can reduce viral particles entering into lungs to $1 \%$ or less than $0.1 \%$ of the reference by improving ambient ventilation, wearing masks, and shorten time of exposure, those measures can make big difference. Even if those efforts fail to prevent an infection on some vulnerable persons, they collectively can make the disease much milder, and reduce death risk and disability risk.

\section{F. WHO and CDC Rules On Use of Masks}

The World Health Organization (WHO) has the following rules as of March 28,2020 [32]:

(1) If you are healthy, you only need to wear a mask if you are taking care of a person with suspected 2019-nCoV infection.

(2) Wear a mask if you are coughing or sneezing.

(3) Masks are effective only when used in combination with frequent handcleaning with alcohol-based hand rub or soap and water.

(4) If you wear a mask, then you must know how to use it and dispose of it properly. 
Those rules are probably based on outcomes from controlled trials. However, when the role of mask is so subtle and viral spreading speed is the most important factor, the decision cannot be based on the outcome of population-based trials [33].

The first rule is incorrect because the pandemic has infected a considerable portion of people, and there is no assurance that air in stories, public places, groceries stores are free from the COVID-19 virus. Rule (2) is incomplete because if the person's coughing and sneezing is caused by COVID19 , then wearing a mask promotes the virus to reach the rest of lungs rapidly. Re-infection speed is a determinant factor in the race between the viral reproduction and adoptive immune response. We also question the Rule 3 for other reasons. While hand cleaning is essential for avoiding risk from generating airborne viral particles, infection caused by physical contact is different. A million viral particles entering into the lungs are much worse than the same virus attacking hands or face surface. This rule reflects a presumption that has been refuted by many model studies we have found [4].

The WHO also maintains the following rules on the use of medical masks to protect against COVID-19 [32]:

(1) Before putting on a mask, clean hands with alcohol-based hand rub or soap and water.

(2) Cover mouth and nose with mask and make sure there are no gaps between your face and the mask.

(3) Avoid touching the mask while using it; if you do, clean your hands with alcohol-based hand rub or soap and water.

(4) Replace the mask with a new one as soon as it is damp and do not reuse single-use masks.

(5) To remove the mask: remove it from behind (do not touch the front of mask); discard immediately in a closed bin; clean hands with alcohol-based hand rub or soap and water.

While precaution is necessary when many things are uncertain, rule (4) reflects an absolute approach. This rule would guide people not to use medical masks even in dangerous situations. An implied assumption is that the mask has captured a great number of viral particles in breathing cycles. If physical contact of the virus that is expected to exist on the mask outer surface is a concern, inhaling all of the viral particles would be a huge worry. Those viral particles would have been more dangerous if they had been breathed into the lungs. Physical contact may redistribute a fraction of the captured viral particles to body parts that are almost immune to viral attacks or generate airborne particles in very low concentration. When no medical mask is available on market, reuse is a rational option. Used masks can be heat-treated in an oven for a sufficiently 
long time to make sure that the virus is inactivated, and inactivated viral particles are tapped off from outside surface of the mask.

The CDC of the U.S. still provides the following rules on use of mask [34] as March 28, 2020:

"Wear a facemask if you are sick[:] If you are sick: You should wear a facemask when you are around other people (e.g., sharing a room or vehicle) and before you enter a healthcare provider's office. If you are not able to wear a facemask (for example, because it causes trouble breathing), then you should do your best to cover your coughs and sneezes, and people who are caring for you should wear a facemask if they enter your room. Learn what to do if you are sick.

If you are NOT sick: You do not need to wear a facemask unless you are caring for someone who is sick (and they are not able to wear a facemask). Facemasks may be in short supply and they should be saved for caregivers."

Those rules are similar to the rules for controlling influenza [35]. Both two rules are opposite to our findings. By following those rules, people do not need to wear a mask when they visit stores, closed public areas, or closed buildings even if they have no control and no knowledge of infected persons. This rule has an effect of keeping the chain of infection active for the population and resulting in worst pandemic disaster. The second rule is really bad because masks can do great harm to infected persons. Therefore, we urge CDC to reverse those two rules as soon as possible.

The CDC suggests that when no mask is available, health workers could "use homemade masks" such as a bandanna or a scarf. We add that due to exposure duration and accumulation of infection probability, the homemade masks are much better than bandanna or a scarf. For health care professionals, protection standard should be much higher because the virus can be accumulated in the lungs in time-dependent process.

Infection cases in Spain, Italy and United States rapidly rise. We suspect that neglecting lung protection is the main reason for the disastrous outcomes. We urge the WHO and CDC to pay attention to lung protection in all closed public areas that lack ample ventilation.

\section{G. Conclusion}

Whether a person should wear a mask depends on the viral traveling direction, which further depends on personal infection status, disease stage, air ventilation condition or wind direction, existence of infected persons, density of people, season, etc. The use of mask interferes with oxygen-carbon dioxide exchanges, increases air humidity, and makes breathing more difficult. It is the only most effective means for preventing the virus from entering the respiratory track at this time. Uninfected persons should wear masks to reduce the number of the viral particles entering the lungs in a closed public area where infected persons may present. Wearing a mask can increase the concentration of virus 
generated from infected tissues and dramatically promote viral re-infection by patient's own virus. An infected person should avoid wearing a mask upon the earliest time of knowing the infection unless the person is under a risk of getting cross infection from the different or more virulent viruses. We urge WHO and CDC to reverse rules on the use of masks for ordinary persons as soon as possible.

\section{LIMITATION OF THIS STUDY}

This study provides principle for determining whether wearing a mask is beneficial to a person. Our approach is contrary to findings from populationbased trials. Whether using of a mask is beneficial depends on viral travel direction, which in turn depends on a large number of external factors and patient health and disease conditions. Any results from controlled trials followed by statistical analysis cannot address the large number of important factors. Randomized controlled trials ignore most of those variables and measure differences between two groups. Such findings cannot be used to any specific person or case. Our model could be developed to study the behaviors of viral particles of different sizes in the future.

\section{FUNDING STATEMENT}

The author(s) declared that no grant was used in support of this research project.

\section{CONFLICT OF INTERESTS}

None

\section{ADDITIONAL INFORMATION}

Additional information is provided in a supplemental document and some information will be stored in igoosa online database. This article may be used by any person for personal use as fair use; any use for research and development and public welfare is permitted by default.

\section{REFERENCES}

(C) All right reserved, Wu \& Zha v100 16 
1. WHO, Coronavirus disease 2019 (COVID-19) Situation Report - 68 Data as reported by national authorities by 10:00 CET 28 March 2020. Accessed at https://www.who.int/emergencies/diseases/novel-coronavirus-2019/situationreports

2. CDC. Coronavirus Disease 2019 (COVID-19), Coronavirus Disease 2019 (COVID-19) in the U.S. Updated March 28, 2020 Accessed at https://www.cdc.gov/coronavirus/2019-ncov/cases-in-us.html

3. Wu, JQ and Zha, P. Preventive, Mitigating and Treatment Strategies for Containing or Ending The COVID-19 Pandemic (a first update) (February 25, 2020). Available at SSRN: https://ssrn.com/abstract $=3544428$ or http://dx.doi.org/10.2139/ssrn.3544428.

4. Wu, JQ and Zha, P. Association of COVID-19 Disease Severity with Transmission Routes and Suggested Changes to Community Guidelines (March 13, 2020). Available at SSRN: https://ssrn.com/abstract $=3554043$ or http://dx.doi.org/10.2139/ssrn.3554043.

5. Ellis, Emory; Delbruck, Max. The Growth of Bacteriophage. The Journal of General Physiology. 1939, 22(3): 365-384.

6. Zwart MP, Hemerik L, Jenny S. et al. An experimental test of the independent action hypothesis in virus-insect pathosystems. Proc. R. Soc. B (2009) 276, 2233-2242.

7. Leeks A, Sanjuán R, and West SA. The evolution of collective infectious units in viruses. Virus Res. 2019 May; 265: 94-101.

8. Vignuzzi M., Stone J. K., Arnold J. J., et al. Quasispecies Diversity Determines Pathogenesis Through Cooperative Interactions in a Viral Population, Nature, 2006, 439: 344-8.

9. Shirogane Y, Watanabe S, Yanagi Y. Cooperation between different variants: A unique potential for virus evolution. Virus Res. 2019 Apr 15;264:6873.

10. Leeks A., Segredo-Otero E.A., Sanjuán R., West S.A. Beneficial coinfection can promote within-host viral diversity. Virus Evol. 2018;4/2.

11. Fabian P., McDevitt JJ, DeHaan WH. Influenza virus in human exhaled breath: an observational study. PLoS One 2008,3, e2691. 
12. Stelzer-Braid S, Oliver BG, Blazey AJ, Argent E, Newsome TP, Rawlinson WD, Tovey ER. Exhalation of respiratory viruses by breathing, coughing, and talking. J Med Virol. 2009B;81:1674-1679.

13. Lindsley WG, Blachere FM, Thewlis RE, Vishnu A, Davis KA, Cao G, Palmer JE, Clark KE, Fisher MA, Khakoo R, Beezhold DH. Measurements of airborne influenza virus in aerosol particles from human coughs. PLoS ONE. 2010;5:e15100.

14. Milton DK, Fabian MP, Cowling BJ, Grantham ML, McDevitt JJ. Influenza virus aerosols in human exhaled breath: particle size, culturability, and effect of surgical masks. PLoS pathogens. 2013;9:e1003205.

15. Lindsley WG, Pearce TA, Hudnall JB, Davis KA, Davis SM, Fisher MA, Khakoo R, Palmer JE, Clark KE, Celik I, Coffey CC, Blachere FM, Beezhold DH. Quantity and size distribution of cough-generated aerosol particles produced by influenza patients during and after illness. J Occup Environ Hyg. 2012;9:443449.

16. Guyton AC. The cough reflex, In Text of Medical Physiology ( $8^{\text {th }}$ Ed). W.B. Saunders Company pg 411-412 (various page rages).

17. Coleman KK., Sigler WV. Airborne Influenza A Virus Exposure in an Elementary School. Scientific Reports volume 10, Article number: 1859 (2020) Scientific Reports volume 10, Article number: 1859 (2020)

18. Brankston G, Gitterman L, Hirji Z, Lemieux C, Gardam M. Transmission of influenza A in human beings. Lancet Infect Dis. 2007;7:257-265.

19. Tellier R. Aerosol transmission of influenza A virus: a review of new studies. J R Soc Interface. 2009;6(Suppl 6):S783-S790.

20. Hall CB. Nosocomial viral respiratory infections: perennial weeds on pediatric wards. Am J Med. 1981;70:670-676.

21. Hall CB, Douglas RG, Jr, Geiman JM, Meagher MP. Viral shedding patterns of children with influenza B infection. J Infect Dis. 1979;140:610-613.

22. Frank AL, Taber LH, Wells CR, Wells JM, Glezen WP, Paredes A. Patterns of shedding of myxoviruses and paramyxoviruses in children. J Infect Dis. $1981 ; 144: 433-441$.

23. Weinstock DM, Gubareva LV, Zuccotti G. Prolonged shedding of multidrug-resistant influenza A virus in an immunocompromised patient. N Engl J Med. 2003;348:867-868. 
24. Sato M, Hosoya M, Kato K, Suzuki H. Viral shedding in children with influenza virus infections treated with neuraminidase inhibitors. Pediatr Infect Dis J. 2005;24:931-932.

25. Glezen WP. Influenza control. N Engl J Med. 2006;355:79-81.

26. Alonso C, Goede DP, Morrison RB, Davies PR, Rovira A, Marthaler DG, Torremorell M. Evidence of infectivity of airborne porcine epidemic diarrhea virus and detection of airborne viral RNA at long distances from infected herds. Vet Res. 2014 Jul 14;45:73. doi: 10.1186/s13567-014-0073-z.

27. Alonso C, Raynor PC., Goyal S, Olson BA, Alba A, Davies PR, Torremorell M. Assessment of air sampling methods and size distribution of virus-laden aerosols in outbreaks in swine and poultry farms. Journal of Veterinary Diagnostic Investigation 2017, Vol. 29(3) 298-304.

28. Arruda AG, Tousignant S, Sanhueza J, Vilalta C, Poljak Z, Torremorell M, Alonso C, Corzo CA. Aerosol Detection and Transmission of Porcine Reproductive and Respiratory Syndrome Virus (PRRSV): What Is the Evidence, and What Are the Knowledge Gaps? Viruses. 2019 Aug 3; 11(8). Epub 2019 Aug 3.

29. Corzo CA, Culhane M, Dee S, Morrison RB, Torremorell M. Airborne Detection and Quantification of Swine Influenza A Virus in Air Samples Collected Inside, Outside and Downwind from Swine Barns. PLoS One. 2013 Aug 8;8(8):e71444.

30. Alonso C, Raynor PC, Davies PR, Torremorell M. Concentration, Size Distribution, and Infectivity of Airborne Particles Carrying Swine Viruses. PLoS One. 2015 Aug 19;10(8):e0135675. doi: 10.1371/journal.pone.0135675. ECollection 2015.

31. Weibel ER. On the Tricks Alveolar Epithelial Cells Play to Make a Good Lung. Am J Respir Crit Care Med Vol 191, Iss 5, pp 504-513, Mar 1, 2015.

32. Coronavirus disease (COVID-19) advice for the public: When and how to use masks. https://www.who.int/emergencies/diseases/novel-coronavirus-2019/ advice-for-public/when-and-how-to-use-masks

33. Wu, JQ and Zha, P. Randomized Clinical Trial Is Biased and Invalid In Studying Chronic Diseases, Compared with Multiple Factors Optimization Trial (November 4, 2019). Available at SSRN: https://ssrn.com/abstract=3480523 or http://dx.doi.org/10.2139/ssrn.3480523 
34. CDC. How to Protect Yourself, Accessed at https://www.cdc.gov/coronavirus/2019-ncov/prevent-getting-sick/prevention.html Last Access on March 28, 2020.

35. Qualls N, Levitt A, Kanade N. et al. Community Mitigation Guidelines to Prevent Pandemic Influenza - United States, 2017. Carrie Reed MMWR Recomm Rep. 2017 Apr 21; 66(1): 1-32. Published online 2017 Apr 21. doi: 10.15585/mmwr.rr6601a1 